DOI: 10.17707/AgricultForest.63.3.22

\begin{abstract}
Hamed HASSANZADEH KHANKAHDANI, Somayeh RASTEGAR, Behrooz GOLEIN, Morteza GOLMOHAMMADI and Abdolhossein ABOUTALEBI JAHROMI ${ }^{1}$
\end{abstract}

\title{
GENETIC DIVERSITY IN PERSIAN LIME (CITRUS LATIFOLIA TANAKA) ACCESSIONS USING MORPHOLOGICAL AND MOLECULAR MARKERS
}

\begin{abstract}
SUMMARY
Persian lime (PL), Citrus latifolia Tanaka, is a triploid and WBDL (Witches Broom Disease of lime) resistant lime which experiences cultivation extension these days. In addition to PL, there are many unknown triploid lime germplasms in the south of Iran, which necessitate to be identified. The current study was conducted to evaluate phylogenetic relationships among PL accessions in Iran. To do so, eighteen known and unknown genotypes of PL and Mexican lime, collected from Fars, Hormozgan and Mazandaran provinces of Iran, as well as eight systematically known citrus varieties were studied by ISSR and morphological markers.

Eight ISSR primers produced 139 polymorphic bands in which polymorphic Information Content (PIC) varied from 0.384 to 0.499 . The morphological study divided examined accessions into two main groups including control accessions (Pummelo, Citron, Lisbon lemon, Sweet lime, Grapefruit and Dancy) and twenty lime and lemon accessions. Both morphological and ISSR markers produced a clear-cut resolution among genotypes and could separate the control accessions from the other ones. Molecular inferred tree grouped all examined accessions and varieties into 7 clades in which Mexican lime accessions (Mexican lime, IFJKh, IFJKMes and Cucumber-shaped lime) and PL accessions grouped in two close groups. As we expected, Persian and Mexican lime accessions showed genetically close relation. The most striking result to emerge from the data was highly correlation between morphological and ISSR data.
\end{abstract}

Keywords: Deperse lime, IAC, Bearss lime, Microsatellites, Tahiti lime.

\footnotetext{
${ }^{1}$ Hamed Hassanzadeh Khankahdani, (corresponding author: Hamed51h@gmail.com), Department of Horticultural Science, Agriculture and Natural Science College, University of Hormozgan, Hormozgan, IRAN and Horticulture Crops Research Department, Agricultural and Natural Resources Research and Education Center of Hormozgan, (AREEO), IRAN. Somayeh Rastegar, Department of Horticultural Science, Agriculture and Natural Science College, University of Hormozgan, Hormozgan, IRAN. Behrooz Golein and Morteza Golmohammadi, Citrus and Subtropical Fruits Research Center, Horticultural Sciences Research Institute, Agricultural Research, Education and Extension Organization (AREEO), Ramsar, IRAN. Abdolhossein Aboutalebi Jahromi, Horticulture Department, Jahrom Branch, Islamic Azad University, Jahrom, IRAN.
}

Notes: The authors declare that they have no conflicts of interest. Authorship Form signed online. 


\section{INTRODUCTION}

PL (Citrus latifolia Tanaka) is a natural triploid citrus species $(2 \mathrm{n}=3 \mathrm{x}=27)$, which rarely produces seeds and is resistant to WBDL (Witches Broom Disease of Lime). No variety has been seen in this species and commercially cultivated genotypes are known as accessions (Santos et al. 2013). Some PL accessions like Bearss lime, Tahitian lime, IAC and Deperse lime have been introduced to Iran through grafted plants or scions from other countries and propagated via budding in various regions of Iran.

In past, phylogenetic relationships among citrus genera and species was only studied based on morphological characteristics, but application of these traits to recognize citrus cultivars is difficult; however, some of these traits are influenced by the environment. Thus, DNA markers have been extensively used to study phylogenetic relationships in many plants (Golein et al. 2013). The intersimple sequence repeat (ISSR) markers are dominant markers which have been used profusely in citrus identification. ISSRs have been used substantially in citrus studies (Sharma et al. 2015). It has been also applied for discrimination among very genetically close cultivars (Tripolitsiotis et al. 2013).

Due to resistance of PL to WBDL (Salehi et al. 2005), its cultivation is being increased in south of Iran regions. In contrast, some genetically unknown lime accessions are cultivated by farmers these days as PL that are infected severely by WBDL. This issue shows that these accessions are not PL and its continuation may have serious implications. Respect with the no published information about genetic diversity of PL, the current study was done to identify PL accessions and its genetic diversity to introduce real PL accessions either for cultivation or for breeding programs. We also aimed to check any correlation between morphological and molecular data in PL to determine whether morphological attributes are affected by environmental factors or not.

\section{Plant material}

\section{MATERIALS AND METHODS}

Leaf sample of the studied genotypes were collected from productive and grafted-seedlings in Fars, Hormozgan and Mazandaran provinces (Table 1). Grapefruit, Pummelo, Lisbon lemon, Citron, Dancy tangerine, Sweet lime and pear-shaped lemon were involved in the study as the control group.

\section{Morphological study}

Morphological attributes study was done by using IPGRI (1999) descriptor list for five trees of each accessions in which various plant attributes such as branch angle, density of branches, tree shape, shoot tip color, spine density, spine shape, leaf lamina shape, leaf lamina margin, leaf apex, leaf length, leaf width, leaf length/width ratio, petiole length, petiole wing situation, petiole wing width, petiole wing shape, color of flower, number of petal, petal length, petal width, pedicle length, calyx diameter, color of anther and anther/stigma ratio. 


\section{DNA extraction and ISSR analysis}

Total genomic DNA was isolated from the young and fresh leaves using the modified EDWARD method (Edward et al. 1991). A total of 14 ISSR primers previously evaluated by other researchers (Shahsavar et al. 2007, Uzun et al. 2010, Martasari et al. 2012, Golein et al. 2013, Tripolitsiotis et al. 2013) were used (table 2).

Table 1: Plant materials utilized for morphological and ISSR analysis

\begin{tabular}{|c|c|c|c|c|}
\hline Genotype name & Accession & Location & Latitude (N) & Longitude (E) \\
\hline Citrus sp. & IFDF & Fars-Darab & $28^{\circ} 19^{\prime} 32^{\prime \prime}$ & $55^{\circ} 11^{\prime} 38^{\prime \prime}$ \\
\hline Citrus sp. & IFD & Fars-Darab & $28^{\circ} 44^{\prime} 58^{\prime \prime}$ & $54^{\circ} 32^{\prime} 59^{\prime \prime}$ \\
\hline Citrus sp. & IFJAb & Fars-Jahrom & $28^{\circ} 31^{\prime} 14^{\prime \prime}$ & $53^{\circ} 40^{\prime} 40^{\prime \prime}$ \\
\hline Citrus sp. & IHRA1 & Hormozgan-Rudan & $27^{\circ} 37^{\prime} 06^{\prime \prime}$ & $57^{\circ} 11^{\prime} 30^{\prime \prime}$ \\
\hline C. latifolia & Persian lime (PL) & Hormozgan-Rudan & $27^{\circ} 37^{\prime} 04^{\prime \prime}$ & $57^{\circ} 11^{\prime} 30^{\prime \prime}$ \\
\hline Citrus sp. & IHRA3 & Hormozgan-Rudan & $27^{\circ} 37^{\prime} 02^{\prime \prime}$ & $57^{\circ} 11^{\prime} 30^{\prime \prime}$ \\
\hline Citrus sp. & IFJAm & Fars-Jahrom & $28^{\circ} 32^{\prime} 32^{\prime \prime}$ & $53^{\circ} 36^{\prime} 30^{\prime \prime}$ \\
\hline Citrus sp. & IFJK & Fars-Jahrom & $28^{\circ} 29^{\prime} 13^{\prime \prime}$ & $53^{\circ} 34^{\prime} 48^{\prime \prime}$ \\
\hline Citrus sp. & IFJM & Fars-Jahrom & $28^{\circ} 30^{\prime} 02^{\prime \prime}$ & $53^{\circ} 36^{\prime} 07^{\prime \prime}$ \\
\hline C. grandis & Pummelo & Mazandaran-Ramsar & $36^{\circ} 54^{\prime} 26^{\prime \prime}$ & $50^{\circ} 39^{\prime} 21^{\prime \prime}$ \\
\hline C. latifolia & Tahiti lime & Hormozgan-Minab & $27^{\circ} 06^{\prime} 27^{\prime \prime}$ & $57^{\circ} 05^{\prime} 39^{\prime \prime}$ \\
\hline C. paradisi & Grapefruit cv. Duncan & Mazandaran-Ramsar & $36^{\circ} 43^{\prime} 04^{\prime \prime}$ & $50^{\circ} 59^{\prime} 02^{\prime \prime}$ \\
\hline C. medica & Citron & Mazandaran-Ramsar & $36^{\circ} 43^{\prime} 04^{\prime \prime}$ & $50^{\circ} 59^{\prime} 02^{\prime \prime}$ \\
\hline C. limon & Lisbon lemon & Mazandaran-Ramsar & $36^{\circ} 43^{\prime} 04^{\prime \prime}$ & $50^{\circ} 59^{\prime} 02^{\prime \prime}$ \\
\hline C. latifolia & Deperse lime & Hormozgan-Minab & $27^{\circ} 06^{\prime} 27^{\prime \prime}$ & $57^{\circ} 05^{\prime} 39^{\prime \prime}$ \\
\hline C. latifolia & IAC & Mazandaran-Ramsar & $36^{\circ} 54^{\prime} 26^{\prime \prime}$ & $50^{\circ} 39^{\prime} 22^{\prime \prime}$ \\
\hline Citrus sp. & IFJAn1 & Fars-Jahrom & $28^{\circ} 27^{\prime} 32^{\prime \prime}$ & $53^{\circ} 31^{\prime} 13^{\prime \prime}$ \\
\hline Citrus sp. & IFJAn2 & Fars-Jahrom & $28^{\circ} 27^{\prime} 32^{\prime \prime}$ & $53^{\circ} 31^{\prime} 12^{\prime \prime}$ \\
\hline C. aurantifolia & Mexican lime & Hormozgan-Rudan & $27^{\circ} 37^{\prime} 02^{\prime \prime}$ & $57^{\circ} 11^{\prime} 29^{\prime \prime}$ \\
\hline Citrus sp. & IFJKMes & Fars-Jahrom & $28^{\circ} 29^{\prime} 13^{\prime \prime}$ & $53^{\circ} 34^{\prime} 46^{\prime \prime}$ \\
\hline Citrus sp. & IFJKh & Fars-Jahrom & $28^{\circ} 32^{\prime} 32^{\prime \prime}$ & $53^{\circ} 36^{\prime} 32^{\prime \prime}$ \\
\hline Citrus sp. & $\begin{array}{l}\text { Cucumber-shaped } \\
\text { lime }\end{array}$ & Fars-Darab & $28^{\circ} 44^{\prime} 58^{\prime \prime}$ & $54^{\circ} 32^{\prime} 59^{\prime \prime}$ \\
\hline C. limon & Pear-shaped lemon & Fars-Darab & $28^{\circ} 44^{\prime} 58^{\prime \prime}$ & $54^{\circ} 32^{\prime} 59^{\prime \prime}$ \\
\hline C. limetta & Sweet lime & Fars-Darab & $28^{\circ} 19^{\prime} 32^{\prime \prime}$ & $55^{\circ} 11^{\prime} 38^{\prime \prime}$ \\
\hline C. reticulata & Dancy tangerine & Mazandaran-Ramsar & $36^{\circ} 43^{\prime} 04^{\prime \prime}$ & $50^{\circ} 59^{\prime} 02^{\prime \prime}$ \\
\hline C. latifolia & Bearss lime & Mazandaran-Sari & $36^{\circ} 38^{\prime} 09^{\prime \prime}$ & $53^{\circ} 11^{\prime} 48^{\prime \prime}$ \\
\hline
\end{tabular}

DNA concentration was measured by NanoDrop 1000 at $260 \mathrm{~nm}$. In addition, quality and intactness of the isolated DNA was tested by $0.8 \%$ Agarose gel. ISSR amplification reactions was prepared to a final volume of $10 \mu \mathrm{l}$ [25 ng 
of template DNA, $0.2 \mathrm{mM}$ dNTPs, $0.5 \mu \mathrm{mol}$ primer $1.0 \mu \mathrm{l}$ of $10 \times$ PCR buffer, 1.5 $\mathrm{mM}$ of $\mathrm{MgCl}_{2}$ and one unit of Taq polymerase (Cinnagen, Iran)]. The amplifications were performed on a PEQStar 96 Universal Gradient 96 wells thermal cycler with reaction conditions programmed as initial pre-denaturation at $95^{\circ} \mathrm{C}$ for $5 \mathrm{~min}$ followed by 39 cycles of denaturation at $94^{\circ} \mathrm{C}$ for $30 \mathrm{~s}$, annealing at $50^{\circ} \mathrm{C}$ for $45 \mathrm{~s}$, and extension at $72^{\circ} \mathrm{C}$ for $2 \mathrm{~min}$. A final $7 \mathrm{~min}$ extension at $72^{\circ} \mathrm{C}$ followed the completion of 39 cycles. After amplification, the DNA fragments were separated by electrophoresis in $1.5 \%$ Agarose gel. The DNA stained using fluoroDye. DNA fragments were visualized and documented with the help of Uvitec Geldoc system.

Table 2: List of the primers used in ISSR analyses

\begin{tabular}{|c|c|c|c|c|c|}
\hline Primer code & Sequences $\left(\mathbf{5}^{\prime}-\mathbf{3}^{\prime}\right)$ & TBN & PBN & P\% & PIC \\
\hline ISSR 1 & BDB(TCC) $)_{5}$ & 16 & 15 & 94 & 0.491 \\
\hline ISSR N3 & DBD(AC) ${ }_{7} \mathrm{~A}$ & 27 & 27 & 100 & 0.384 \\
\hline ISSR N5 & $(\mathrm{AG})_{8} \mathrm{YT}$ & 17 & 17 & 100 & 0.499 \\
\hline ISSR N7 & $(\mathrm{AC})_{8} \mathrm{YG}$ & 16 & 16 & 100 & 0.426 \\
\hline ISSR 809 & $(\mathrm{AG})_{8} \mathrm{G}$ & 19 & 19 & 100 & 0.436 \\
\hline ISSR 810 & $(\mathrm{GA})_{8} \mathrm{~T}$ & 17 & 17 & 100 & 0.480 \\
\hline ISSR 814 & $(\mathrm{CT})_{8} \mathrm{~A}$ & 9 & 9 & 100 & 0.386 \\
\hline ISSR 844 & $(\mathrm{CT})_{8} \mathrm{AGC}$ & 20 & 19 & 95 & 0.487 \\
\hline \multicolumn{7}{r}{ Mean } & 17.6 & 17.4 & 98.6 & 0.449 \\
\hline
\end{tabular}

*Y: Pyrimidine, B: non-A, D: non-C, Total band number (TBN), Polymorphic band number (PBN), Polymorphic percent (P\%) and Polymorphic information content (PIC).

\section{Data analysis}

The data from the mean morphological attributes were used to design a dissimilarity matrix calculated from the mean Euclidian distance. The relative contribution of each attribute to the diversity among accessions was assessed (Singh, 1981) by NTSYS software ver. 2.02 (Rohlf, 2005). By scoring amplified fragments, ISSR products were translated to numerical data as either 1 (present) or 0 (absent) of band. A pair-wise similarity matrix was constructed using Dice similarity. Dendrogram constructed using NTSYS software based on Complete algorithm. Polymorphism information content (PIC) was calculated using the formula: PIC=2fi(1-fi), where $f i$ is the frequency of the amplified allele (present band), and (1-fi) is the frequency of the null allele (absent band) (Roldan-Ruiz et al. 2000). Mantel test used for matrix correlation between morphologic and genetic distance using IBDWS ver. 3.23 (Jensen et al. 2005). Principal coordination analysis (PCA) was performed based on ISSR data using NTSYS software version 2.02. 


\section{Morphological study}

\section{RESULTS}

Among the studied morphological attributes, leaf and flower traits could group well the accessions. The cluster inferred from morphological data showed that similarity coefficient (SC) ranging between $0.27-1.00$ and mean similarity was 0.44 (Figure 1). It showed that the IFD and PL had the most relation with the 1.00 similarity. In contrast, the Pummelo had the most dissimilarity with the other accessions; with 0.28 SC. Morphological-derived phylogenetic tree divided all accessions into two main groups. Whereby, control accessions including Pummelo, Citron, Lisbon lemon, Sweet lime, Grapefruit and Dancy clustered in the same group. The second group including twenty lime and lemon accessions in which Tahiti lime had the closest similarity with Deperse lime (0.93). The evaluated accessions were grouped into five clades, according to Figure 1.

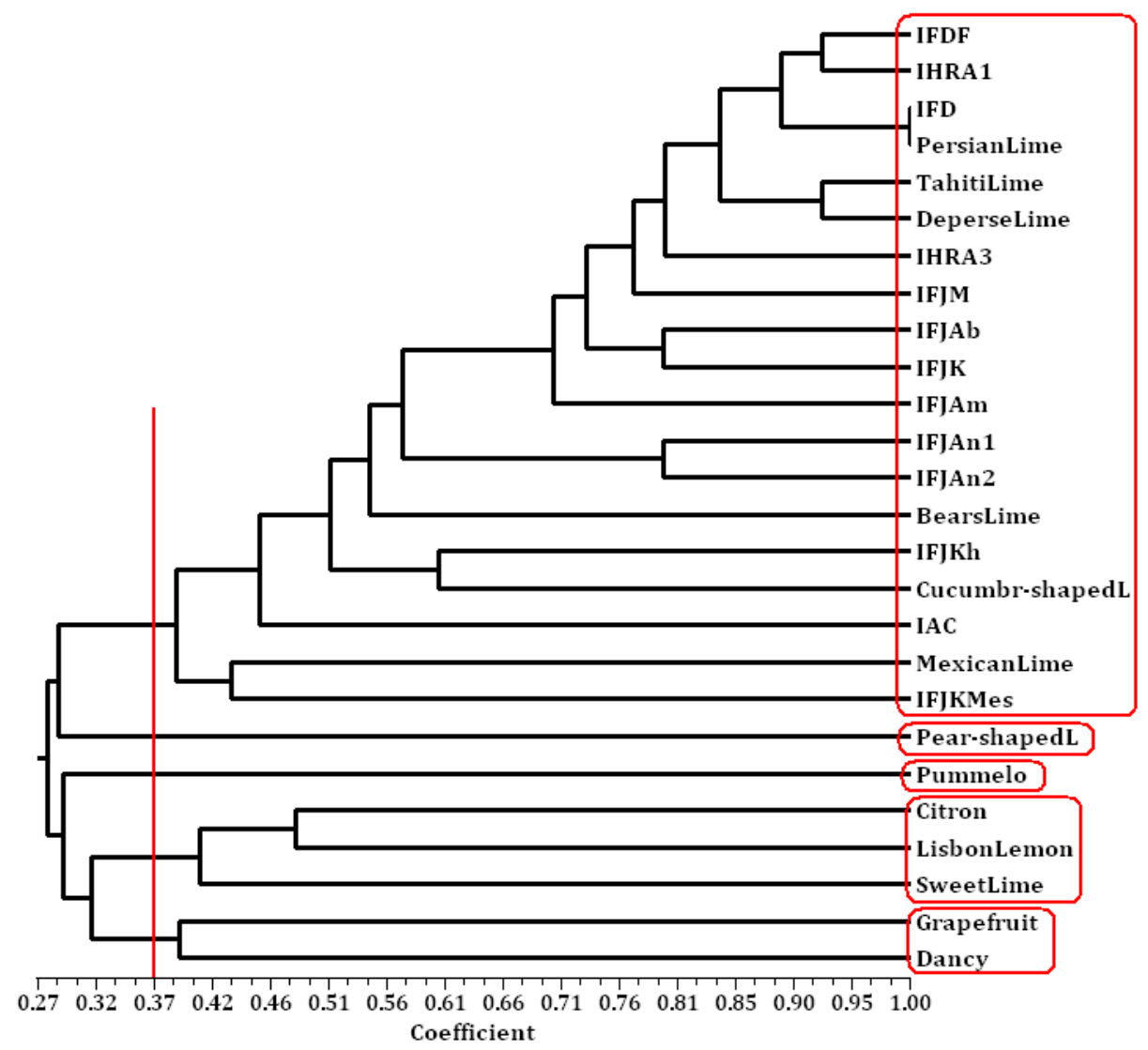

Figure 1: Genetic similarity among 26 citrus accessions. The dendrogram generated using UPGMA clustering method based on the similarity matrix containing 26 morphological markers. 


\section{ISSR analysis}

ISSR data showed that eight out of 14 primers were polymorphic. In total, 141 bands were produced in which 139 were polymorphic (Table 2). The ISSR markers showed 99\% polymorphic bands, with a mean of 17.4 polymorphic bands per primer. Polymorphic percent rate (P\%) varied from $100 \%$ (in N3, N5, N7, 809, 810 and 814) to $94 \%$ (in ISSR 1), so that the mean of polymorphic percent was 99\%. Average PIC value for the used primers was 0.449 (Figure 2).

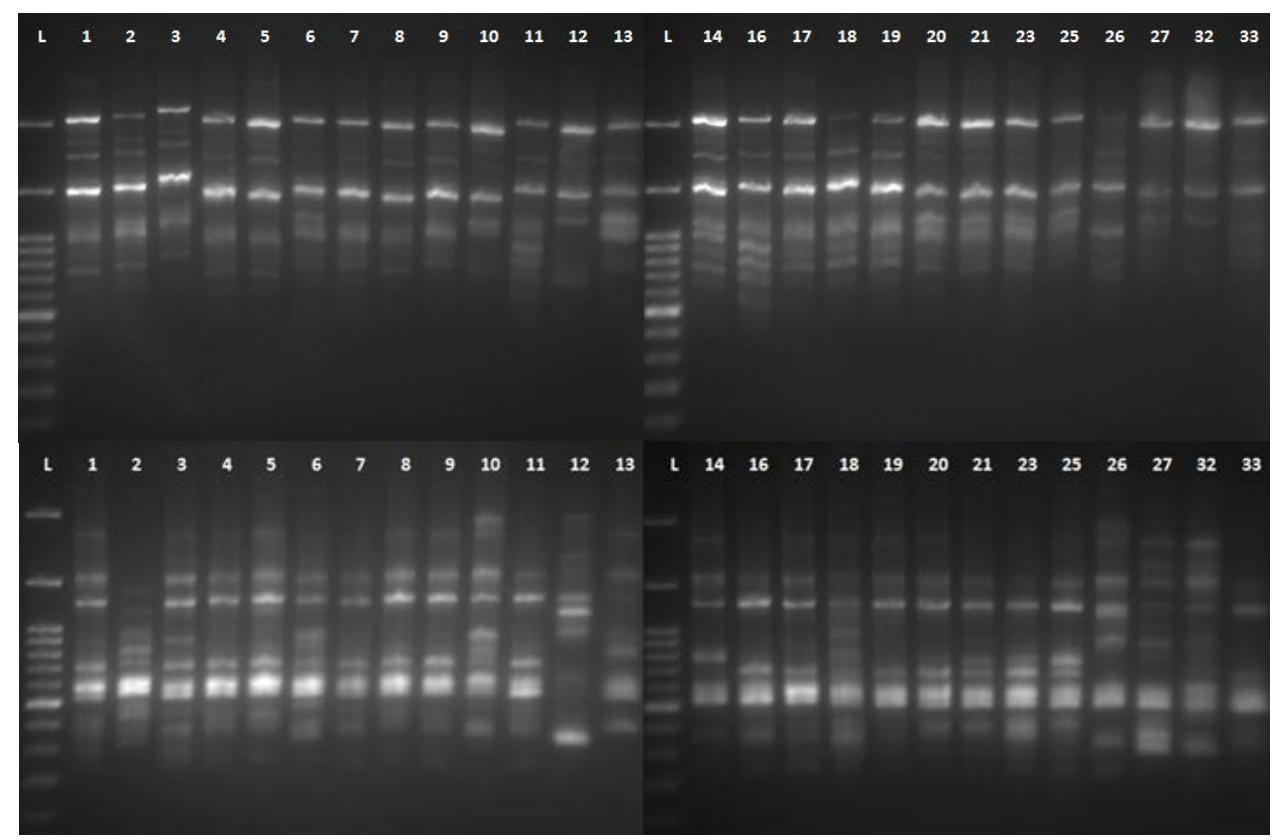

Figure 2: ISSR profiles amplified from DNA of Citrus accessions using primer ISSR N5 (above) and ISSR 844 (below). L: Ladder (100-3000 bp), 1: IFDF, 2: IFD, 3: IFJAb, 4:IHRA1, 5: Persian lime, 6: IHRA3, 7: IFJAm, 8: IFJK, 9: IFJM, 10: Pummelo, 11: Tahiti lime, 12: Grapefruit, 13: Citron, 14: Lisbon lemon, 16: Deperse lime, 17: IAC, 18: IFJAn1, 19: IFJAn2, 20: Mexican lime, 21: IFJKMes, 23: IFJKh, 25: Cucumber-shaped lime, 26: Pear-shaped lemon, 27: Sweet lime, 32: Dancy tangerine, 33: Bearss lime.

Molecular analysis clustered all accessions into two main groups: the first group including Dancy, Sweet lime, Citron, Grapefruit and Pummelo, and the second group including all limes and lemons accessions. According to the reference line, all accessions divided into seven clades as shown in Figure 3. In G1, Dancy tangerine separated from the other accessions. In G2, Sweet lime and Citron; in G3, Grapefruit; in G4, Pummelo and in G5, Pear-shaped lemon and Lisbon lemon separated from others. In G6, Deperse lime, four accessions of Mexican lime, Bearss lime, IFJAn1, IFJAn2, IAC and Tahiti lime detached from the other Persian limes with 0.57 SC (Figure 3). G7 clade was consisting the accessions of Persian lime that it has been recently propagated in south of Iran 
(Fars provinces) and it has been planted in both Fars and Hormozgan provinces. Pairwise similarity coefficient among mentioned accessions varied from 0.730.96 (Figure 3).

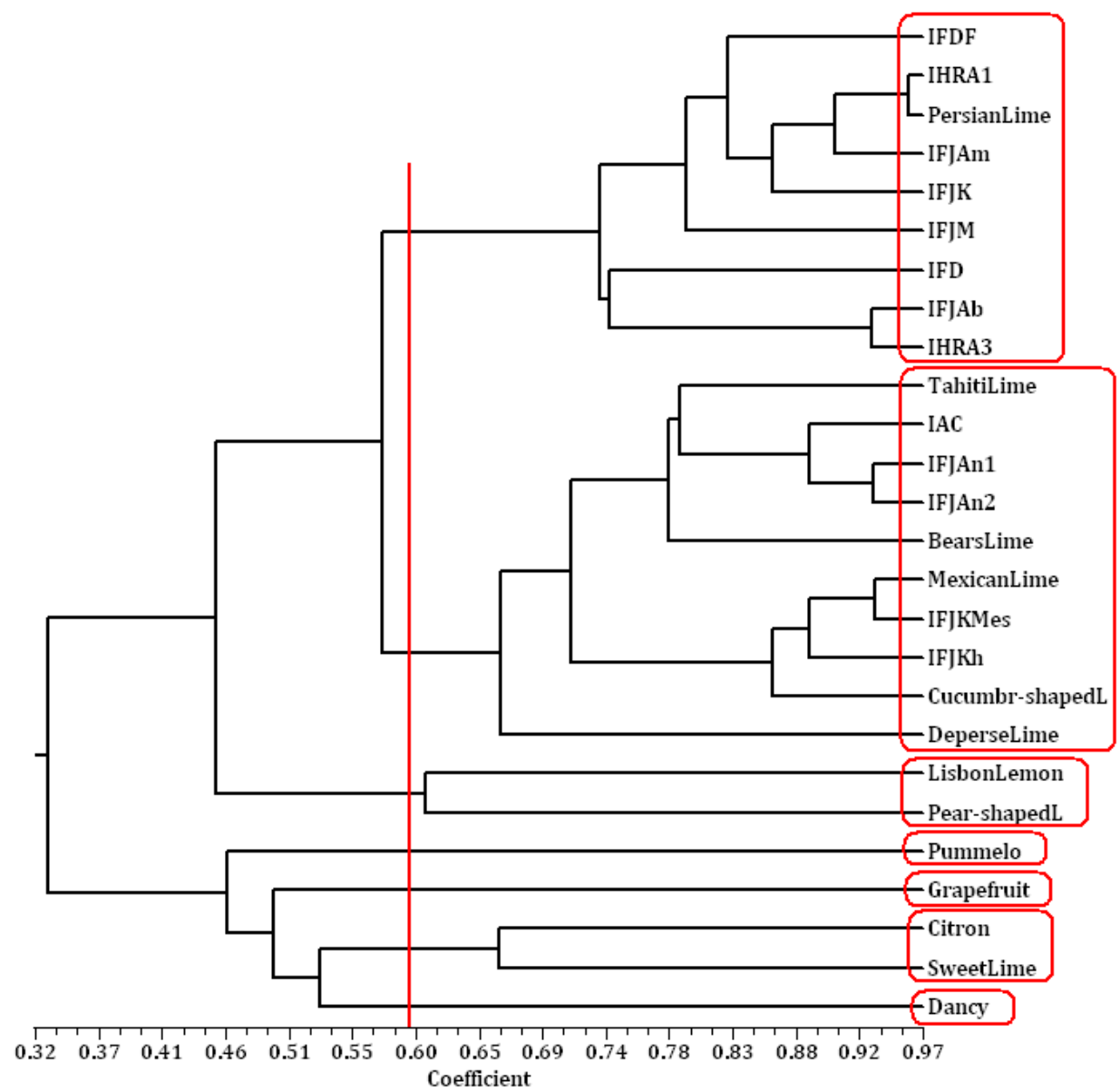

Figure 3: Dendrogram designed for 26 citrus accessions using ISSR markers based on Complete algorithm and Dice similarity coefficient.

Deperse lime, Bearss lime, Tahiti lime, IAC and PL are well-known accessions among the studied PL accessions which have been introduced to Iran from other countries. The other PL accessions in the present study have been propagated by budding method using the collected scions from geneticallyunknown mother plants cultivated in Fars province.

The lowest similarity coefficient (0.57) was observed between Deperse lime and the other PL accessions (Deperse lime was placed in a separate clade of G6). However, IHRA1 and PL had the highest similarity coefficient (0.96). Bearss lime had the greatest similarity coefficient (0.78) with Tahiti lime, IAC, IFJAn1 and IFJAn2. Tahiti lime had high similarity (0.79) with IAC, IFJAn1 and 
IFJAn2 accessions. Similarity coefficient among IAC and IFJAn1 and IFJAn2 accessions was 0.89 . The PCA divided the studied accessions into seven main groups similar to what obtained by molecular analysis (Figure 4).

\section{Correlation between morphological and ISSR data}

The partial Mantel test showed significant correlation between morphological and ISSR data $(\mathrm{r}=0.739 ; \mathrm{p}<0.01)$.

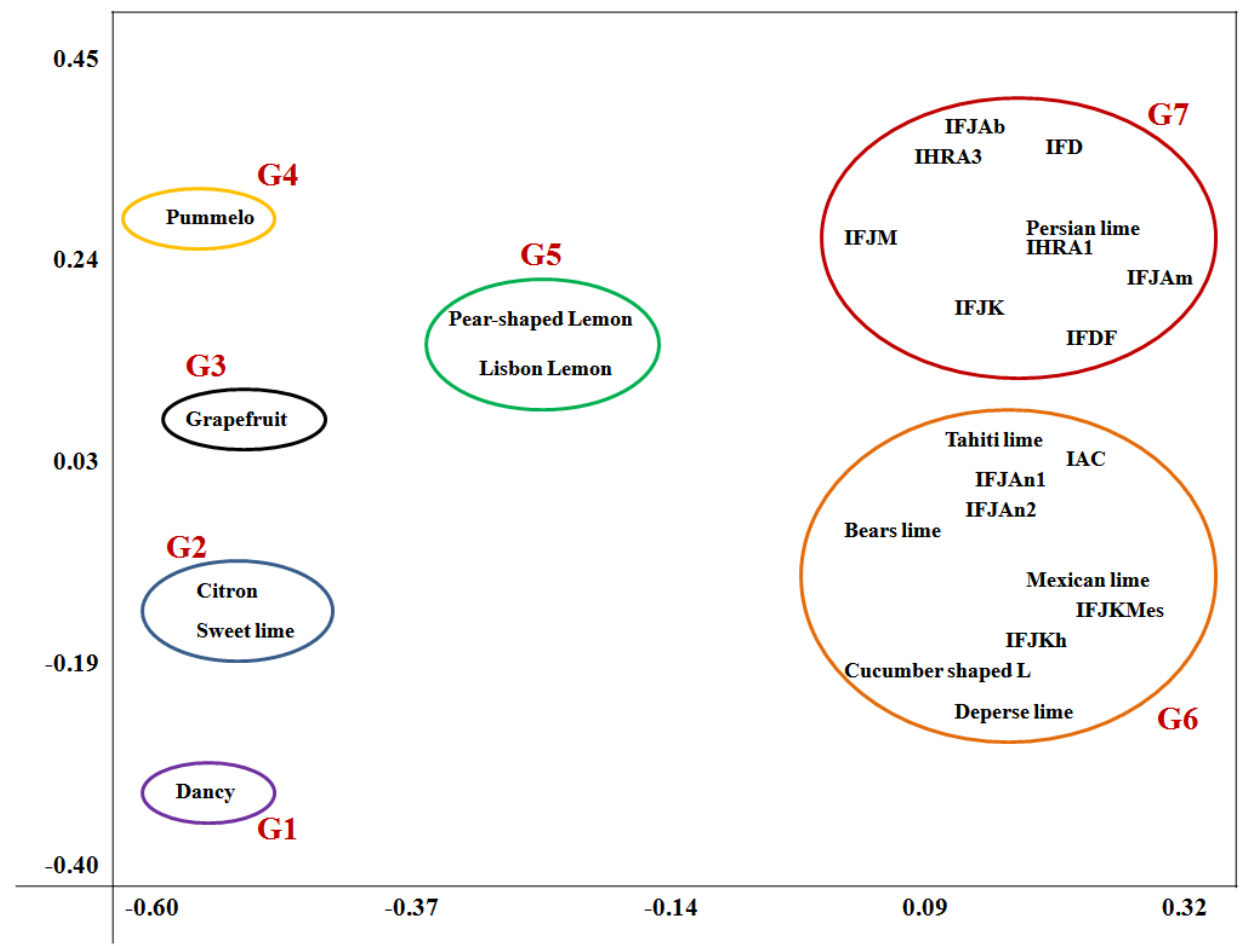

Figure 4: Principal Coordinate Analysis (PCA) based on ISSR data from the evaluated accessions.

\section{DISCUSSION}

Both morphological and molecular markers used in this study, resulted in clear-cut resolution among the studied genotypes and confirmed each other which show there is a deep correlation between these two markers. Comparison of morphological and molecular outcomes is a key factor to conclude the extent of genetic diversity present in the set of cultivars (Sharma et al. 2015). In our study, there was positive and significant correlation between both morphological and ISSR markers $\left(\mathrm{r}=0.739^{* *}\right)$, which were in agreement with the findings on sweet orange cultivars (Malik et al. 2012) and lime accessions (JahangirzadehKhiavi et al. 2016).

Our results also revealed close relation between PL accessions and Mexican lime but no with the other genotypes. It has been showed that there was no difference among selections of PL such as IAC-5, Persian 58 and Bearss lime 
(Santos et al. 2013), which is not according to our findings. It has been believed PL is not a separate species, but is a natural hybrid of the group formed by citronlemon-lime. In Brazil and Florida, USA, it is known as Tahiti lime and in California, USA, as Bearss lime (Rivera-Cabrera et al. 2010). In the present study, the obtained similarity coefficient from ISSR data between lime (Persian and Mexican) and lemons accessions (Lisbon lemon and Pear-shaped lemon) was 0.45 , which is in accordance to the findings of other researchers (Santos et al. 2013). They reported a separation between lemon and acid lime trees.

The similarity coefficient from ISSR analyses were $0.86-0.94$ between Mexican lime and three unknown lime accessions i.e. IFJKMes, IFJKh and Cucumber-shaped lime. The above mentioned accessions are similar to Mexican lime and they have been derived from sexual propagation of Mexican lime. It has been reported that Cucumber-shaped lime probably generated from hybridization limes and lemons accessions; however, it had far genetic distance from lemons (Shahsavar et al. 2007). Mexican lime was propagated by seed in Iran. Mexican lime seeds are poly-embryonic (Momtaz-Khan et al., 2017), in which one of the embryos has sexual origin and the others result from nucellar tissue of embryo sac. Accordingly, high variation is seen among these seed born accessions and it has been used as a potential tool in WBDL resistance trials. Similarity coefficients between Mexican lime and PL accessions (known and unknown accessions) were 0.57-0.71. Other scholars placed Mexican lime and Tahiti lime in the same cluster with 0.82 SC (Shahsavar et al. 2007).

Tahiti lime resulted from lime by citron or lemon hybridization but they could not recognize its triploid status (Reece and Childs 1962). The identity of Persian, Tahiti and Bearss limes are explained by their diffusion (Morton, 1987). It has been reported that Tahiti lime has been obtained through bud sport selection (Qin et al. 2015). It has been found Citrus latifolia accessions (Tahiti, Bears, Persian, El-Kseur and IAC-5) probably resulted from the fertilization of a haploid gamete of $C$. limon by a diploid gamete of C. aurantifolia (Curk et al. 2016). Based on our unpublished data, all of the morphological accessions attributed to PL were triploid while Mexican lime, IFJKMes, IFJKh, and Cucumber-shaped lime were diploid.

\section{CONCLUSION}

Rapid prevalence of WBDL in the south of Iran and high susceptibility of Mexican lime to that resulted in demanding a WBDL-resistant lime species. PL is a WBDL-resistant lime species which has been considered greatly by farmers for replacing Mexican lime. However, apart from its desired properties, no documented information is available about it. Molecular analysis of PL accessions using ISSR primers revealed divergence of Deperse lime from the other PL accessions. Tahiti lime, Bearss lime, IAC and two morphologically related accessions to PL namely IFJAn1 and IFJAn2 had close relation and placed in the same clade. The other accessions attributed to PL including IFDF, IHRA1, IFJAm, IFJK, IFJAb, IHRA3, IFJM and IFD also placed in the same 
clade beside PL accession. On the other hand, three accessions related to Mexican lime including IFJKh, IFJKMes and Cucumber-shaped lime had close relation with Mexican lime and high similarity coefficient. Generally, according to both morphological and ISSR markers, the control accessions separated from other accessions. Mexican lime accessions including Mexican lime, IFJKh, IFJKMes and Cucumber-shaped lime placed into the same clade. As we expected, Persian and Mexican lime accessions showed close genetic relation. The most striking result to emerge from the data was highly correlation between morphological and ISSR outcomes, which was supported phylogenetic clustering.

\section{ACKNOWLEDGMENT}

This work was a section of enormous design to obtain technical knowledge and production of lime tolerant cultivars against WBDL and to start and revenue from genetic resources of Iran's lime under design no. 11.65555, which was supported by Vice-Presidency for Science and Technology.

\section{REFERENCES}

Curk F, Ollitrault F, Garcia-Lor A, Luro F, Navarro L, Ollitrault P. 2016. Phylogenetic origin of limes and lemons revealed by cytoplasmic and nuclear markers. Ann Bot-London, 1-19.

Edwards K, Johnstone C, Thompson C. 1991. Simple rapid method for the preparation of plant genomic DNA for PCR analysis. Nucleic Acids Res., 19(6): 1349.

Golein B, Ghasemi M, Fattahi Moghadam J, Gholamian E. 2013. Genetic analysis between unknown citrus accessions and commercially important cultivars using ISSR marker. Agri Biotech J., 5(4): 111-124. (In Persian with English abstract)

IPGRI. 1999. Descriptors for Citrus. International Plant Genetic Resources Institute, Rome, Italy.

Jahangirzadeh-Khiavi S, Hamidpghli Y, Golein B, Sabouri A. 2016. Assessment of lime genetic diversity in three regions of Iran, using morphological and ISSR markers. Agri Comm., 4(3): 18-29.

Jensen J, Bohonak A, Kelley S. 2005. Isolation by distance, web service, Version 3.23. BMC Genet., 6: 13.

Malik S, Rohini M, Kumar S, Choudhary R, Pal D, Chaudhury R. 2012. Assessment of genetic diversity in Sweet orange cultivars of India using morphological and RAPD markers. Agri Res., 1: 317-324.

Martasari C, Karsinah R. 2012. Characterization of Indonesian Siam cultivar by morphological and ISSR markers. ARPN J Agri Biol Sci., 7(10): 830-835.

Momtaz-Khan M, Yahyai R, Al-Said F. 2017. Introduction and overview of Lime. CAB International, $11 \mathrm{pp}$.

Morton J. 1987. Tahiti Lime. In: Morton JF, ed. Fruits of warm climates. Miami, FL.

Qin Y, Xu C, Ye Z, DaSilva J, Hu G. 2015. Seedless mechanism of a new citrus cultivar Huami Wuhegonggan. Pakistan J Bot., 47(6): 2369-2378. 
Reece P, Childs J. 1962. Character differences among seedlings of the Persian lime. P Fl St Hortic Soc., 75: 110-116.

Rivera-Cabrera F, Ponce-Valadez M, Sanchez F, Villegas-Monter A, Perez-Flores L. 2010. Acid limes; a review. Fresh Produce, Global Sci Books, 4(1): 116-122.

Rohlf F. 2005. NTSYS-pc, numerical taxonomy and multivariate analysis system. Version 2.02. Exeter Software, Setauket, New York.

Roldan-Ruiz I, Calsyn E, Gilliland T, Coll R, vanEijk M, DeLoose M. 2000. Estimating genetic conformity between related ryegrass varieties. 2. AFLP characterization. Mol Breeding, 6: 593-602.

Salehi M, Nejat N, Tavakoli A, Izadpanah K. 2005. Reaction of Citrus cultivars to Candidatus Phytoplasma aurantifolia in Iran. Plant Dis., 41: 363-376. (In Persian with English abstract)

Santos M, Passos O, Soares Filho W, Girardi E, Gesteira A, Ferreira C. 2013. Variability analysis of Persian acid lime tree selections using agronomic and molecular markers. Genet Mol Res., 12(4): 4604-4614.

Shahsavar A, Izadpanah K, Tafazoli E, Sayed Tabatabaei B. 2007. Characterization of citrus germplasm including unknown variants by ISSR markers. Sci HorticAmsterdam, 112: 310-314.

Sharma N, Dubey A, Srivastav M, Singh B, Singh A, Singh N. 2015. Assessment of genetic diversity in grapefruit cultivars using physico-chemical parameters and microsatellite markers. Aust J Crop Sci., 9(1): 62-68.

Singh D. 1981. The relative importance of characters affecting genetic divergence. Indian J Genet Pl Br., 41: 237-245.

Tripolitsiotis C, Nikoloudakis N, Linos A, Hagidimitriou M. 2013. Molecular characterization and analysis of the Greek citrus germplasm. Not Bot Horti Agro., 41(2): 463-471.

Uzun A, Gulsen O, Yesiloglu T, Aka-cakar Y, Tuzcu O. 2010. Distinguishing grapefruit and pummelo accessions using ISSR markers. Czech J Genet Pl Br., 46(4): 170-177. 